\title{
REDESCRIÇÃO DE PARALAPPIDA LIMBATIVENTRIS (STÅL, 1862) (HEMIPTERA: FULGOROMORPHA: DICTYOPHARIDAE)
}

\author{
Marcelo da Silva Baptista
}

Biota Neotropica v3 (n2) http://www.biotaneotropica.org.br/v3n2/pt/abstract?short-communication+BN00703022003

Recebido em: $14 / 05 / 2003$

Revisado em: 27/06/2003

Publicado em: 01/07/2003

Museu de Entomologia, Departamento de Biologia Animal, Centro de Ciências Biológicas e da Saúde, Universidade Federal de Viçosa (www.ufv.br), CEP: 36571-000, Viçosa, Minas Gerais, Brasil.

Correspondência: e-mail: baptistams@insecta.ufv.br

\begin{abstract}
Redescription of Paralappida limbativentris (Stål, 1862) (Hemiptera: Fulgoromorpha: Dictyopharidae).

Paralappida limbativentris (Hemiptera: Fulgoromorpha: Dictyopharidae) was redescribed based_on specimens from the states of Rio de Janeiro and Minas Gerais, Southeastern Brazil. Characters of the head, wings, and legs are described and illustrated. The male and female genitalia are described and illustrated for the first time.
\end{abstract}

Key words: Insecta, Auchenorrhyncha, Fulgoroidea, Neotropics, Brazil.

\section{Resumo}

Redescrição de Paralappida limbativentris (Stål, 1862) (Hemiptera: Fulgoromorpha: Dictyopharidae).

Paralappida limbativentris (Hemiptera: Fulgoromorpha: Dictyopharidae) é redescrita com base em exemplares provenientes dos estados do Rio de Janeiro e de Minas Gerais, Região Sudeste do Brasil. Características da cabeça, asas e pernas são descritas e ilustradas. As genitálias do macho e da fêmea são descritas e ilustradas pela primeira vez.

Palavras-chave:Insecta, Auchenorrhyncha, Fulgoroidea, Neotrópico, Brasil.

http://www.biotaneotropica.org.br 


\section{Introdução}

Paralappida Melichar, 1912 é um dos gêneros neotropicais de Dictyopharidae (Auchenorrhyncha: Fulgoroidea) menos conhecidos com respeito à morfologia e taxonomia. Paralappida pode ser diferenciado de outros gêneros neotropicais principalmente através do estigma reticulado, característica esta somente apresentada pelo gênero africano Philoteria Melichar, 1912; carena marginal da fronte sinuosa e o ápice da projeção, alargado e truncado, e com duas depressões frontais. Essa última característica foi denominada por Melichar (1912) como "schweinsrüsselartig" (i.e., semelhante a um focinho de porco). O gênero Paralappida está registrado para os estados de Santa Catarina (Melichar,1912; Schmidt,1915), Rio de Janeiro (Stål, 1862; Melichar,1912), São Paulo e Espírito Santo (Melichar,1912), sendo presentemente registrado para o Estado de Minas Gerais.

Stål (1862) inicialmente descreveu três espécies no gênero Pseudophana Burmeister, 1835. Entretanto, o próprio autor, no mesmo trabalho, transferiu duas das três espécies descritas para o gênero Lappida e a terceira foi incluída no gênero Nersia Stål, 1862. Posteriormente, Melichar (1912) estabeleceu o gênero Paralappida, baseado nas espécies Pseudophana constricta Stål, 1862 e P. limbativentris Stål, 1862 e ao descrever Paralappida, com base nas espécies descritas por Stål, 1862, utilizou na lista de sinonímias das espécies somente as designações originais. Melichar (1912) também sinonimizou Paralappida com Pseudophana Stål (nec Burmeister, 1835), não atentando para o detalhe que a terceira espécie foi mantida no gênero Nersia. Melichar (1912), ao designar a espécie Pseudophana limbativentris como a espécie-tipo de Paralappida, renomeou-a como "Paralappida limbatinervis" [err. typogr. (Metcalf, 1946)], nome este mantido por Schmidt (1915).

Metcalf (1946) apresentou pela primeira vez $L$. limbativentris e L. constricta como sinônimos das espécies de Paralappida e designou a série-tipo como sendo os espécimes listados por Schmidt (1915), depositados por Melichar no Stettiner Museums, Alemanha, e procedentes do Estado de Santa Catarina, Brasil. Porém, a localidadetipo supostamente seria o Estado do Rio de Janeiro, Brasil, na descrição original de Stål (1862). Metcalf (1946) também considerou como "ortótipo" (termo obsoleto) $P$. limbatinervis Melichar, 1912, desconsiderando totalmente a descrição original de Pseudophana limbativentris Stål, 1862.

Schmidt (1915) listou as espécies de Dictyopharidae que foram depositadas por Melichar no Stettiner Museums, na lista foi incluída apenas $P$. limbativentris. $\mathrm{O}$ gênero Paralappida também foi citado por Metcalf (1938), em uma chave modificada de Melichar (1912) para os gêneros americanos, e por Fennah (1944), que o incluiu em uma chave para os Dictyopharidae do Novo Mundo.

\section{Materiais e Métodos}

Neste trabalho, $P$. limbativentris é redescrita a partir de espécimes depositados em diferentes coleções entomológicas no Brasil. A espécie foi identificada com base nas descrições originais de Stål (1862) e de Melichar (1912), atentando principalmente para a coloração e a morfologia da cabeça. Em uma análise mais acurada da espécie, pôdese rever com maior detalhe a morfologia da cabeça, as asas anteriores e posteriores e as pernas. As genitálias do macho e da fêmea são particularmente significativas, uma vez que estão sendo descritas e ilustradas pela primeira vez. Para as genitálias do macho e da fêmea foram empregadas as terminologias de Sing-Pruthi (1925) e Bourgoin (1993) para Auchenorrhyncha, Fulgoromorpha.

$\mathrm{O}$ material examinado pertence às coleções entomológicas das seguintes instituições: Museu de Zoologia da Universidade de São Paulo (MZSP); Departamento de Zoologia, Instituto de Biologia da Universidade Federal do Rio de Janeiro (DZRJ), e Museu Regional de Entomologia da Universidade Federal de Viçosa (UFVB).

Material Examinado - BRASIL, Minas Gerais: Juiz de Fora, L.B.N. Coelho col., 04/ii/1987, 19(DZRJ); Viçosa, E.W. Teixeira col., 22/v/1999, $1 \not{\delta}$ (UFVB). Rio de Janeiro: Angra dos Reis, Ilha Grande, Sampaio \& Carvalho col., 20-28/ii/ 1984, 19 (DZRJ); Nova Friburgo, Mury, Gred \& Guimarães col., xii/1975, 1 (MZSP).

\section{Resultados}

\subsection{Resdescrição - Paralappida limbativentris (Stål, 1862)}

Comprimento total - 16 a $17 \mathrm{~mm}(\vec{\delta})$ e 18 a $19 \mathrm{~mm}(\stackrel{9}{q})$. Cabeça (Figs. 1-3) - Vértice alaranjado com região anterior marrom e pequena porção central da borda anterior branca; comprimento $3,5 \mathrm{x}$ a largura da base; carena mediana em toda extensão do vértice (exceto em pequena região no terço mediano); carenas marginais esbranquiçadas, com uma constrição antes dos olhos e uma leve reentrância na metade distal, afastando-se no ápice; ápice com mesma largura da base; margem posterior reta; largura da cabeça (incluindo os olhos) 1,5x a largura da base do vértice. Face lateral da extensão da cabeça marrom; coloração amarelo-pálida abaixo dos olhos; faixa negra atrás dos olhos na borda pós-ocular; carena marginal da fronte sinuosa no meio da projeção; sutura subgenal reta. Ápice da projeção entre vértice e fronte (Fig. 3) truncado, largura 1,8x o comprimento; coloração negra com centro alaranjado, uma mancha mediana branca 

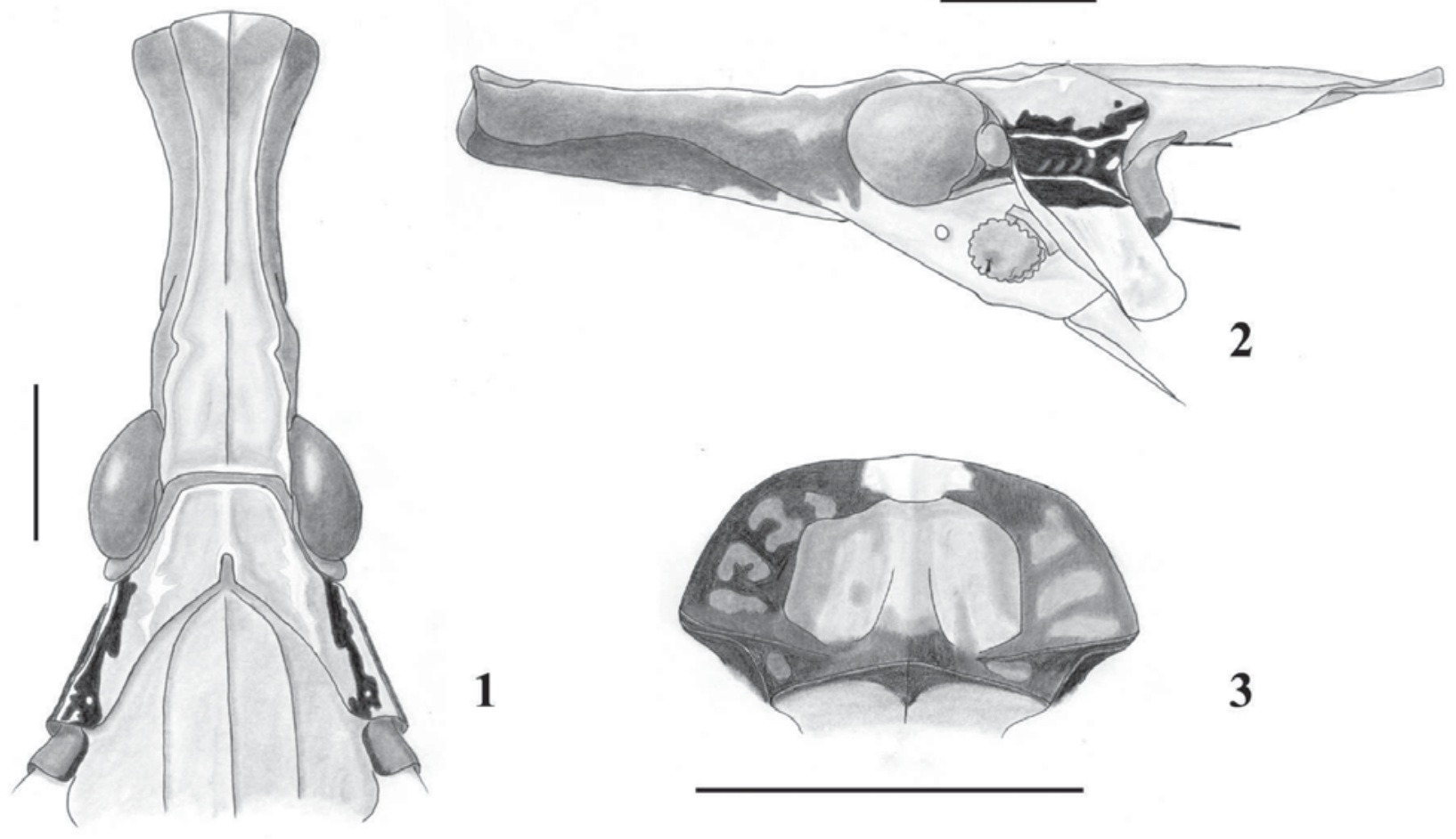

1

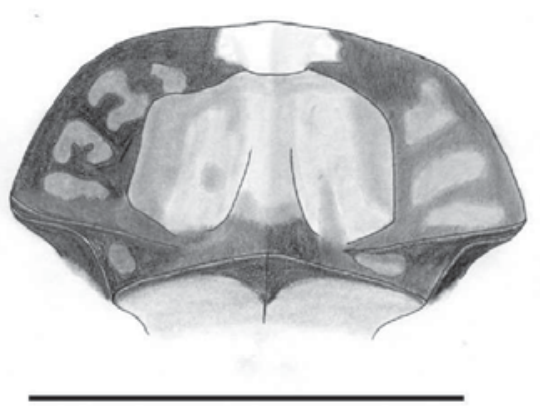

3

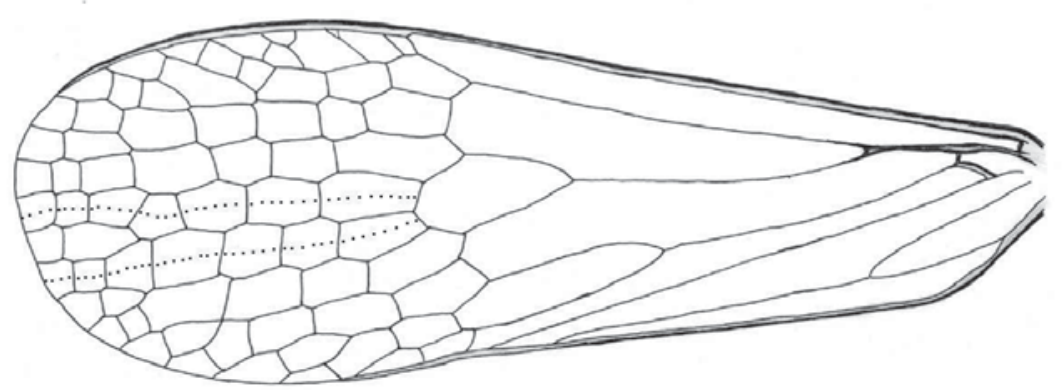

4

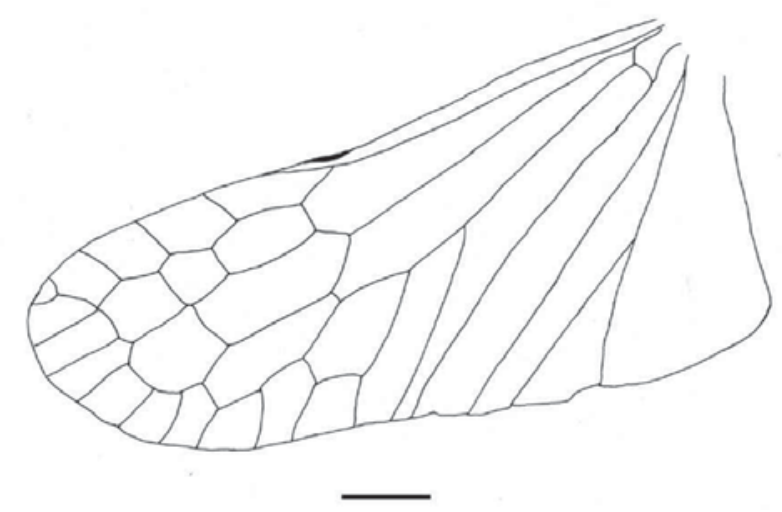

Figuras 1 - 5. Paralappida limbativentris (Stål, 1862), macho adulto. 1. Cabeça, pronoto e mesonoto (vista dorsal). 2. Cabeça, pronoto e mesonoto (vista lateral). 3. Ápice da projeção da cabeça (transição vértice/fronte). 4. Asa anterior esquerda. 5. Asa posterior esquerda. (Escalas $1 \mathrm{~mm})$. 

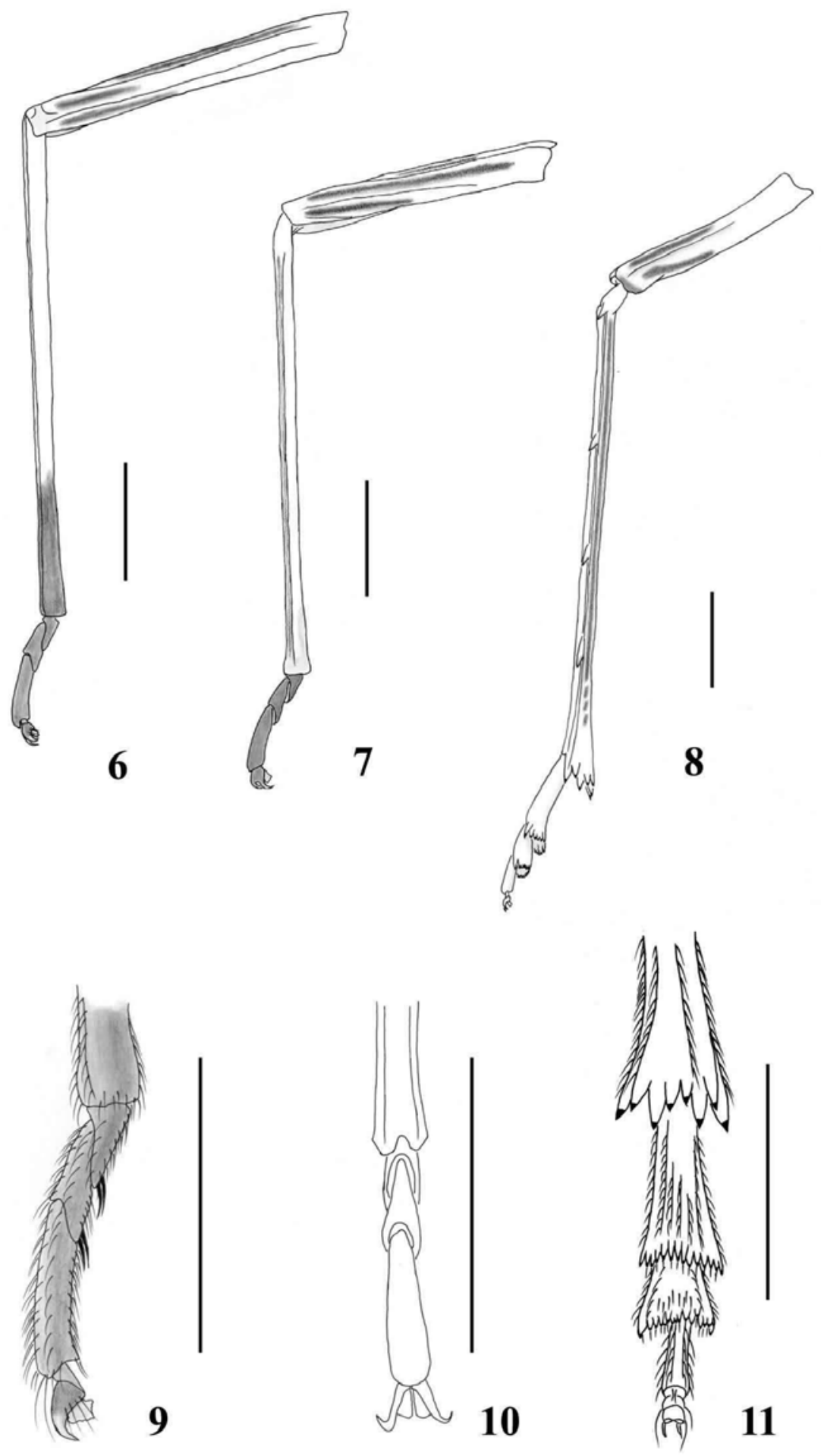

Figuras 6 - 11. Paralappida limbativentris (Stål, 1862), macho adulto. 6. Perna (fêmur, tíbia e tarso) anterior esquerda (vista lateral). 7. Perna (fêmur, tíbia e tarso) mediana esquerda (vista lateral). 8. Perna (fêmur, tíbia e tarso) posterior esquerda (vista lateral). 9. Tarso anterior esquerdo (vista lateral). 10. Tarso anterior esquerdo (vista dorsal). 11. Tarso posterior esquerdo (vista ventral). (Escalas $1 \mathrm{~mm}$ ). 

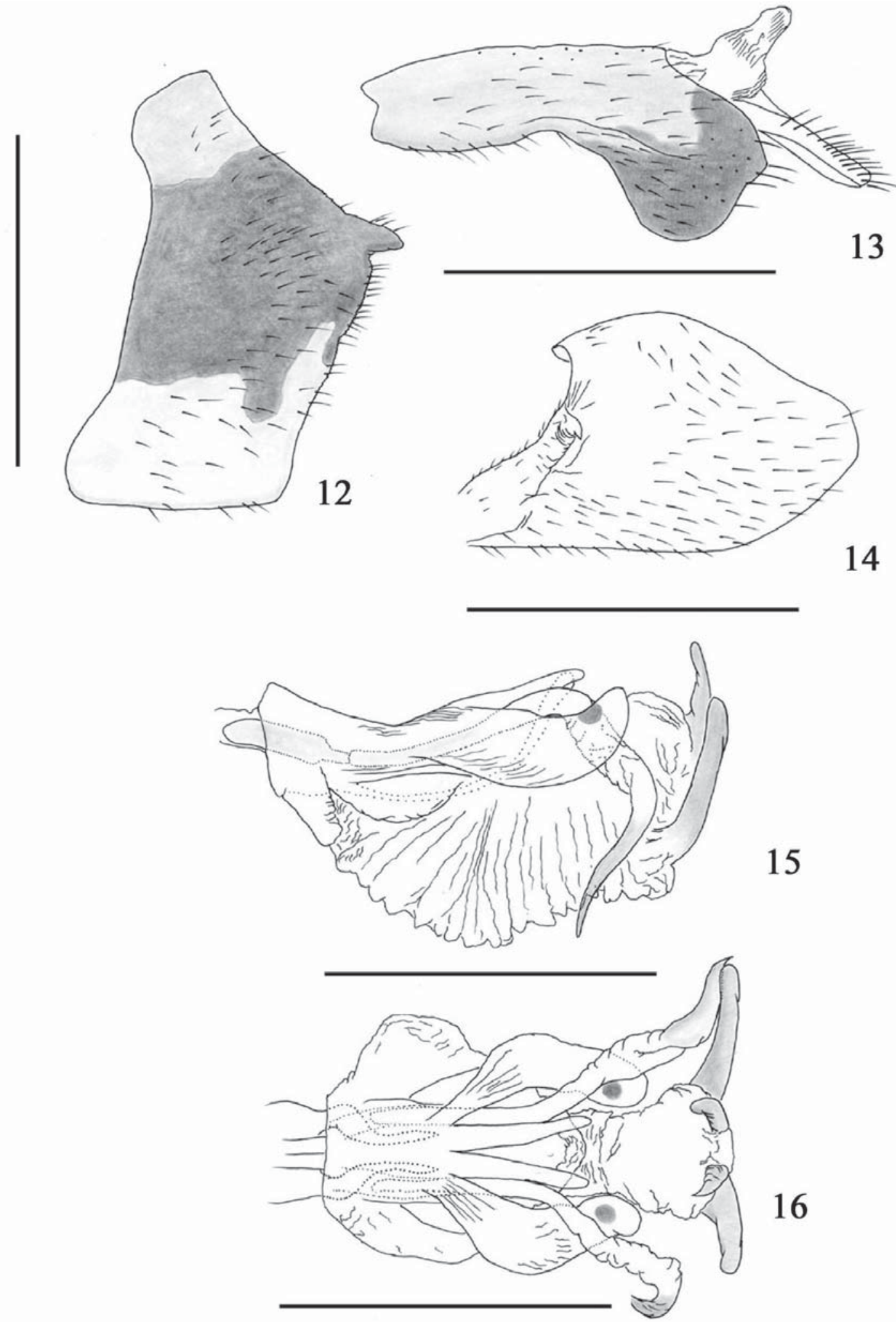

Figuras 12 - 16. Paralappida limbativentris (Stål, 1862), macho adulto. 12. Pigóforo $\delta^{\mathfrak{h}}$ (vista lateral). 13. Placa anal $\delta^{-3}$ (vista lateral).

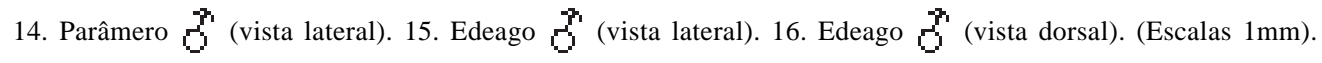




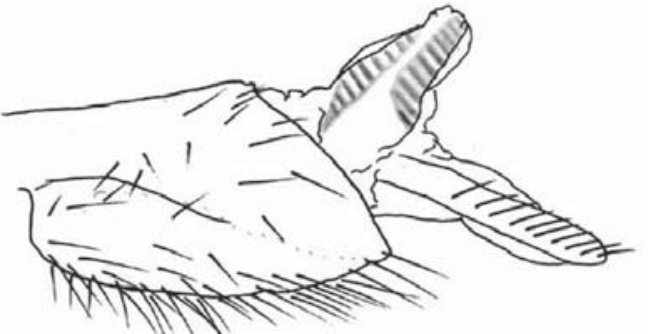

17
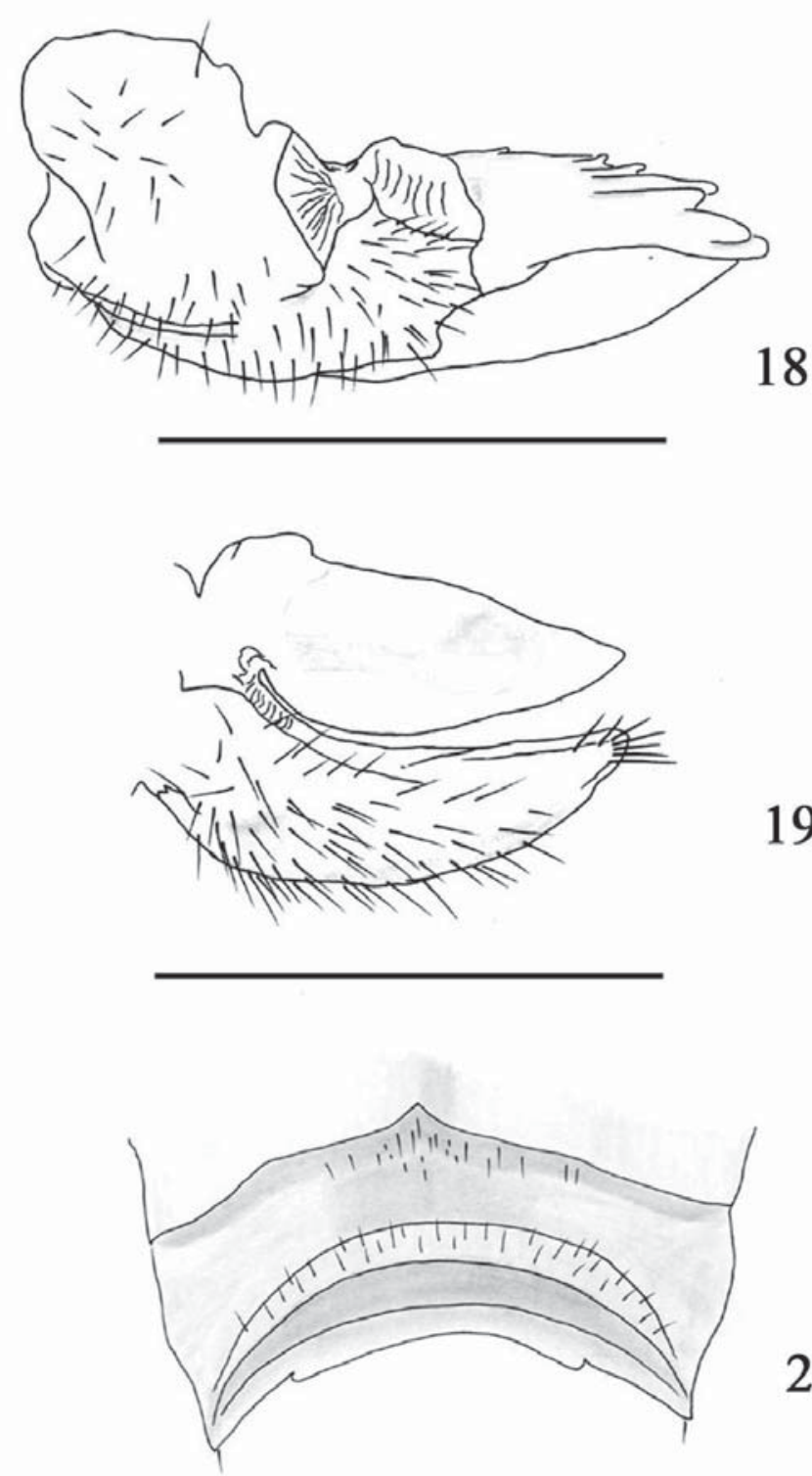

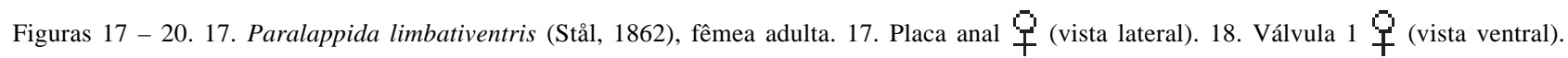
19. Válvula 39 (vista lateral). 20. Sétimo esternito 9 (vista ventral). (Escalas $1 \mathrm{~mm}$ ). 
na borda superior e manchas laterais marrons; carena mediana atravessando o ápice. Fronte amarelo-pálida com ápice marrom, tricarenada; carenas laterais nos dois terços apicais, carena mediana fracamente marcada no terço mediano; carena marginal levemente expandida à frente da antena; segundo antenômero arredondado, esverdeado e com mais de 60 sensilas placóides; sutura frontoclipeal côncava; sutura transclipeal reta; anteclípeo e pós-clípeo tricarenados (uma carena mediana e duas marginais). Labro medianamente marrom e carenado. Extremidade do segmento apical do lábio marrom.

Tórax (Figs. 1-2) - Pronoto e mesonoto juntos medindo $1,1 \mathrm{x}$ o comprimento do vértice; pronoto alaranjado dorsalmente, com faixa longitudinal negra na lateral e região inferior amarelo-pálida; carenas mediana e laterais brancas, alcançando a margem posterior; margem anterodorsal reta; margem posterior com forte reentrância central; carenas marginais e pleurais esbranquiçadas; mesoescuto alaranjado com três carenas paralelas; reduplicação do escutelo escurecido. Tégula marrom com as bordas superior e inferior negras; restante do tórax amarelo-pálido. Asa anterior (Fig. 4) hialina com margem costal negra ventralmente e marrom dorsalmente; comprimento (linha mediana) 3,1x a largura [linha nodal (distância entre a base do estigma e o ápice da sutura claval)]; seis fileiras de células na membrana; estigma reticulado com seis a sete células; estigma e região apical do setor mediano marrom; Sc+R bifurcada próxima à linha nodal; $\mathrm{R}$ com três ramos; $\mathrm{M}$ bifurcada no terço distal do cório antes de $\mathrm{Sc}+\mathrm{R} ; \mathrm{M}_{1+2}$ e $\mathrm{M}_{3+4}$ bifurcadas na linha nodal; $\mathrm{M}_{1}, \mathrm{M}_{3}$ e $\mathrm{M}_{4}$ com dois ramos; $\mathrm{M}_{2}$ simples; $\mathrm{CuA}$ bifurcada antes de $\mathrm{M}$; $\mathrm{CuA}_{1}$ com dois ramos; $\mathrm{CuA}_{2}$ simples; $A_{1}$ e $A_{2}$ fusionadas no terço basal do clavo; $\mathrm{Sc}+\mathrm{R}+\mathrm{M}$ bifurcada na mesma distância que na fusão das anais; células entre $M_{2}$ e $M_{3}, M_{3}$ e $M_{4}$ com dobra na membrana (Fig. 4). Asa posterior (Fig. 5) com setor radial com cinco ramos; $\mathrm{M}_{1+2}$ e $\mathrm{M}_{3+4}$ fusionadas até região apical; $\mathrm{Cu} \mathrm{A}_{1}$ com cinco ramos. Pernas (Figs. 6-11) amarelas com coxa e trocanter amarelo-pálidos; tíbia e fêmur com seção transversal hexagonal; tíbias com três faces mais largas e três mais estreitas; face dorsal da tíbia com margem apical sulcada; garras tarsais marrons com extremidade marromclara e com quatro cerdas laterais. Pernas anteriores e medianas: fêmures com áreas escurecidas na margem apical, região central das faces negra; tíbia 1,5x o tamanho do fêmur; faces maiores anterior e mediana da tíbia com região central negra; último tarsômero anterior e mediano $2 \mathrm{x}$ o comprimento dos demais somados; terço distal das tíbias anteriores e tarsos marrons ou negros; tarsos medianos marrons ou negros. Perna posterior (Fig. 8) - fêmures com a metade distal das faces escurecida no centro; tíbias posteriores 3,1x o tamanho do fêmur, com quatro espinhos laterais negros no ápice; ápice da tíbia com oito espinhos $\left(\begin{array}{lll}1 & 2 & 1 \\ 1 & 1 & 1\end{array}\right)$; região central da face ventral da tíbia negra; tarsômero 1 com 14 espinhos; tarsômero 2 com 16 espinhos.
Abdome - Tergitos abdominais alaranjados com bordas laterais negras e esternitos amarelo-pálidos.

Genitália do macho (Figs. 12-16) - Pigóforo com mesmo padrão de coloração do abdome; margem posterior lateralmente serrilhada e com processo espinhoso curto e robusto; região ventral $2 \mathrm{x}$ mais larga que a região dorsal. Placa anal dorsalmente alaranjada, ventralmente côncava, com extremidades posterolaterais negras e estendidas ventralmente; estilo anal com cerdas laterais. Parâmeros negros; subovalados, com região apical robusta; ápice da margem superior dobrado para dentro; espinho lateral com a base na margem anterior e posicionado perpendicularmente. Edeago: conjuntiva tubular, fortemente dilatada ventralmente; expansão ventral na base; um par de expansões laterais na metade anterior; um par de extensões dorsolaterais com regiões subapicais esclerosadas e pequenos espinhos na extremidade; ápice da conjuntiva com dois pares de espinhos direcionados para cima; um par dorsoapical e outro ventroapical medindo $2 \mathrm{x}$ o tamanho do primeiro; falossoma bifurcado na metade apical, com dois gonóporos; espinho direcionado para baixo, com ápice esclerosado.

Genitália da fêmea (Figs. 17-20) - Placa anal ventralmente côncava, relativamente curta e arredondada, com $0,5 x$ o comprimento do macho; muitas cerdas nas bordas laterais. Válvula 1 com sete projeções dorsais robustas e truncadas na lâmina conectiva anterior, direcionadas para trás; fíbula anterior curta; lobo endogonocoxal estreito e alongado. Válvula 2, fusionada, com pequena expansão ventoapical como nos demais gêneros. Válvula 3 côncava, curvada para cima; região apical com sete cerdas grossas na face lateral. Sétimo esternito com metade posterior da superfície elevada, em forma de meia lua; margem posterior com extensão mediana curta e larga.

\section{Discussão}

Yemel'yanov (1983) criou uma chave para tribos de Dictyopharidae, na qual incluiu Paralappida em Nersiini, porém salientou que o gênero apresenta uma posição ainda duvidosa ao nível de tribo. Apesar da posição duvidosa, e baseado somente em características da genitália da fêmea, o autor incluiu o gênero em Nersiini, apoiando-se nos seguintes caracteres: ausência de cerdas no tubo anal; parte inferior da válvula 3 não apresentando uma margem membranosa no ápice. Foram observadas nesta primeira descrição das genitálias do macho e da fêmea características bastante distintivas para o gênero Paralappida. A genitália da fêmea segue o padrão semelhante dos demais gêneros de Dictyopharidae, entretanto esse é o único gênero que apresenta as projeções na válvula 1 direcionadas para trás, diferenciando do padrão geral de Dictyopharidae, em que tais projeções são curvadas e direcionadas lateralmente. A 
elevação em forma de meia lua e a extensão da margem posterior do sétimo esternito também não foram descritas para outros gêneros de Dictyopharidae.

Fennah (1944), na descrição da genitália do macho de Nersia florida Fennah,1944, ressaltou o fato da espécie apresentar uma conjuntiva tubular. Apesar do macho de $P$. limbativentris também apresentar o edeago com uma conjuntiva tubular, a semelhança entre os gêneros é muito pequena. A presença de extensões posterolaterais na placa anal do macho e a dilatação da conjuntiva na região ventral do edeago são características que distinguem bastante o padrão apresentado em Paralappida. As extensões posterolaterais_na placa anal e os dois pares de espinhos no ápice da conjuntiva são características jamais descritas para outros gêneros neotropicais.

Segundo as descrições originais de Stål (1862), os padrões de coloração das duas espécies de Paralappida são muito semelhantes, porém a morfologia das espécies apresenta algumas diferenças com respeito ao tamanho do processo cefálico e ao número de espinhos na tíbia posterior, sendo descrita $P$. constricta com cinco espinhos. Melichar (1912) também ressaltou a diferença no tamanho da cabeça, apresentando $P$. limbativentris com o comprimento da cabeça 2,3x o de $P$. constricta (Stål, 1862), e diferenças na coloração da asa anterior, na qual $P$. limbativentris apresenta o estigma "leitoso", e $P$. constricta tem o estigma avermelhado, descrevendo, porém, ambas as espécies com o mesmo número de espinhos (quatro) na tíbia posterior.

\section{Agradecimentos}

À Coordenação de Aperfeiçoamento de Pessoal de Nível Superior (CAPES) pelo auxílio financeiro. Aos Pesquisadores Dr. Paulo Sérgio Fiuza Ferreira (UFV), Dr. Jorge Luiz Nessimian (UFRJ) e Dr. Ubirajara Martins (MZSP) pelo empréstimo do material e aos Professores Carlos Raphael Lugo-Ortiz, José Eduardo Serrão (UFV) e Elidiomar Ribeiro da Silva (UNI-RIO) pelo auxílio na elaboração.

\section{Referências Bibliográficas}

BOURGOIN, T. 1993. Female genitalia in Hemiptera Fulgoromorpha, morphological and phylogenetic data. Ann. Soc. Entomol. France (N.S.), 29(3): 225-244.

FENNAH, R.G. 1944. New Dictyopharidae from the New World (Homoptera: Fulgoroidea). Proc. Biol. Soc. Wash. 57: 79-94.

MELICHAR, L. 1912. Monographie der Dictyophorinen (Homoptera). Abh. Zool. Bot. Gesel. Wien 7(1): 1-221.

METCALF, Z.P. 1938. The Fulgorina of Barro Colorado and other parts of Panama. Bull. Mus. Comp. Zool. 82: 277423.

METCALF, Z.P. 1946. General Catalogue of the Homoptera.
Fascicle IV Fulgoroidea. Part 8 Dictyopharidae. North Carolina State College, Raleigh, NC, USA. p. 1-246.

SCHMIDT, E. 1915. Die Dictyopharinen des Stettiner Museum (Hemiptera - Homoptera). Stet. Entomol. Zeit. 76: 345-358.

SINGH-PRUTHI, H. 1925. V. The morfology of the male genitalia in Rhynchota. Trans. Entomol. Soc. London, I, II: 127-267.

STÅL, C. 1862. Bidrag till Rio de Janeiro-traktens Hemipterfauna II. Kong. Svenska Vet. Akad. Handl. 3(6): 1-75.

YEMEL'YANOV, A.F. 1983. Dictyopharidae from Cretaceous doposits on the Taymyr Peninsula (Insecta, Homoptera). Paleont. Zhur. 3: 79-85.

Título: Redescrição de Paralappida limbativentris (Stål, 1862) (Hemiptera: Fulgoromorpha: Dictyopharidae)

Autor: Marcelo da Silva Baptista

Biota Neotropica, Vol. 3 ( número2): 2003

http://www.biotaneotropica.org.br/v3n2/pt/ abstract?short-communication+BN00703022003

Recebido em: 14/05/2003

Revisado em: 27/06/2003

Publicado em: 01/07/2003

ISSN 1676-0603 